\title{
Multiple calcinosis cutis as a result of Köbner phenomenon in a patient with systemic sclerosis
}

\section{Toshiyuki Yamamoto}

\author{
Department of Dermatology, Fukushima Medical University, Fukushima 960-1295, Japan
}

Corresponding author: Prof. Toshiyuki Yamamoto, E-mail: toyamade@fmu.ac.jp

Sir,

Calcification is a well-known cutaneous manifestation of systemic sclerosis $(\mathrm{SSc})$. We herein report a case of SSc who developed small calcified nodules on the both thumbs, which was considered to be as a result of Köbner phenomenon.

A 65-year-old female was hospitalized in the Department of Urology of our university hospital because of renal malignancy. She was referred to the Department of Dermatology for the examination of Birt-Hogg-Dube syndrome. On physical examination, there were no cutaneous and mucosal papulonodular lesions suggestive of Birt-Hogg-Dube syndrome; however, there were many whitish firm small nodules on both thumbs (Fig. 1). Furthermore, she had swollen fingers on both hands, and dot hemorrhages on the nailfolds of the right third and fourth fingers. She noticed finger coldness and Raynaud's phenomenon for these a few years. Skin biopsy was not performed due to the patient's refusal. Laboratory examination showed positive anti-nuclear antibody (1:2560) and anti-centromere antibody $(178 \mathrm{U} / \mathrm{ml}$; normal $<10)$, while negative anti-Scl-70 and SS-A antibodies. X-ray findings showed features of multiple soft tissue calcifications around the phalanges of both thumbs (Fig. 2). Although further examination denied lung fibrosis, pulmonary hypertension, and esophagitis, she was diagnosed with SSc. She did not wish to undergo surgical therapy for the nodules.

Calcinosis cutis is a well-known skin manifestation in patients with $\mathrm{SSc}$, with a frequency between $18 \%$ and $49 \%$ [1]. Several factors including male gender, digital ulcers, digital pitting scars, acroosteolysis, telangiectasias, anticentromere antibody, and

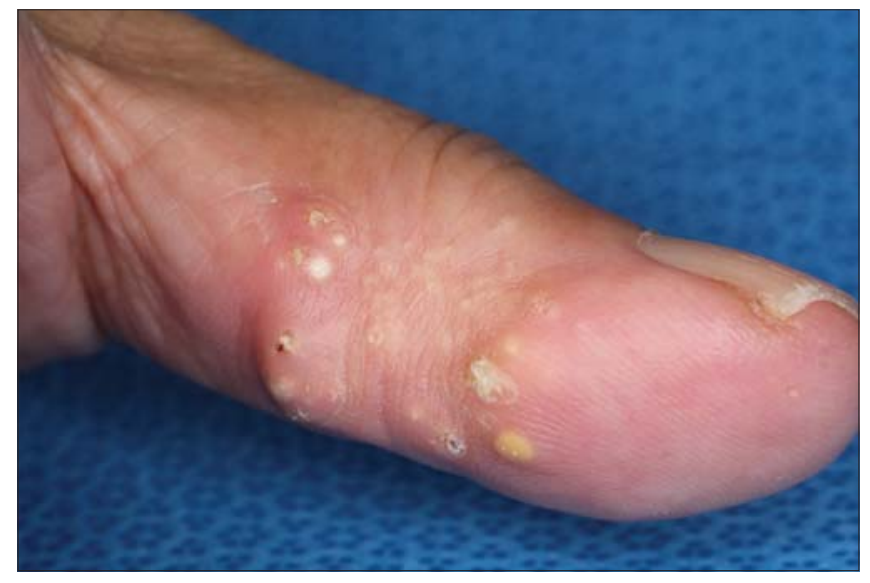

Figure 1: Multiple, whitish firm nodules on the pad of the thumb.

anti-PM/Scl antibody have been suggested to associate with the development of calcinosis cutis in SSc [2-4].

In the present case, a number of small nodules were observed on the fingers ob both hands. Her husband was a timber dealer, and she often tied timbers together at their home timberyard. Thus, she was engaged in labor work using hands for long duration, which was speculated to be closely linked to the development of calcified nodules limited to both thumbs. Trauma may be an aggravating factor of calcification in SSc. The frequently involved sites are extremities, especially hands [5], which are susceptible to mechanical stimuli. Gauhar et al. showed that the thumb was more frequently affected by calcinosis than the other digits, followed by the index finger [6], suggesting that repetitive (micro)trauma results in tissue injury predisposing to dystrophic calcification. Calcinosis typically occurs long after the diagnosis of SSc, i.e. more than 10 years after the diagnosis $[7,8]$; however, in the present case, the patient developed multiple calcified

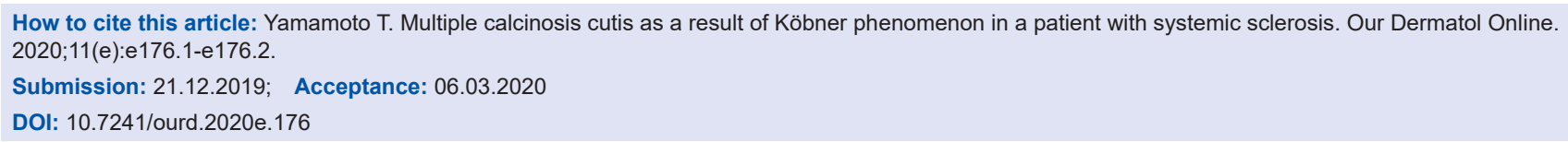




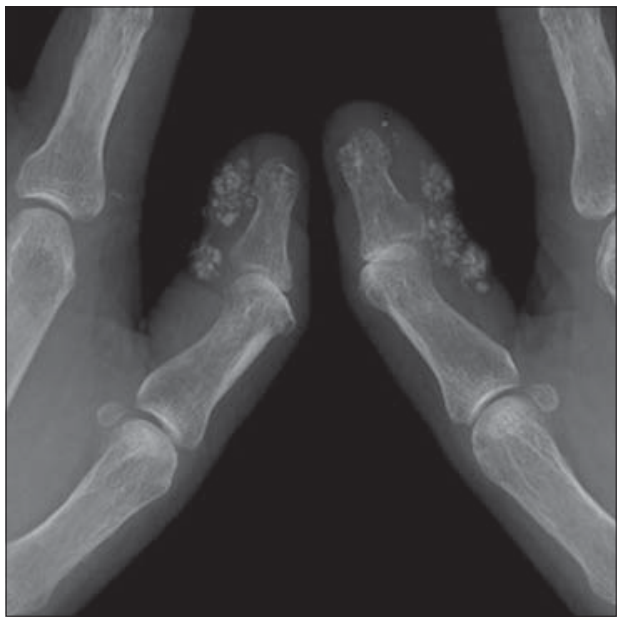

Figure 2: X-ray showing 'wet cotton-wool appearance' of calcinosis.

nodules due to Köbner phenomenon, unassociated with disease duration. She did not visit a hospital and thus was not diagnosed with SSc previously, although she noticed Raynaud's phenomenon.

The etiology of dystrophic calcification is not fully elucidated, and chronic inflammation, vascular hypoxia, local trauma, and dysregulation of bone matrix proteins have been speculated as potential mechanisms. The present case indicates that calcified nodules developed as a result of Köbner phenomenon.

\section{Consent}

The examination of the patient was conducted according to the Declaration of Helsinki principles.
The authors certify that they have obtained all appropriate patient consent forms. In the form the patient(s) has/have given his/her/ their consent for his/her/their images and other clinical information to be reported in the journal. The patients understand that their names and initials will not be published and due efforts will be made to conceal their identity, but anonymity cannot be guaranteed.

\section{REFERENCES}

1. Valenzuela A, Song P, Chung L. Calcinosis in scleroderma. Curr Opin Rheumatol. 2018;30:554-61.

2. Baron M, Pope J, Robinson D, Jones N, Khalidi N, Docherty P, et al. Calcinosis is associated with digital ischemia in systemic sclerosis: a longitudinal study. Rheumatology. 2016;55:2148-5.

3. Johnstone EM, Hutchinson CE, Vail A, Chevance A, Herrick AL. Acro-osteolysis in systemic sclerosis is associated with digital ischaemia and severe calcinosis. Rheumatology. 2012;51:2234-8.

4. Pai S, Hsu V. Are there risk factors for scleroderma-related calcinosis? Mod Rheumatol. 2018;28:518-22.

5. Bartoli F, Fiori G, Braschi F, Amanzi L, Bruni C, Blagojevic J, et al. Calcinosis in systemic sclerosis: subsets, distribution and complications. Rheumatology. 2016;55:1610-14.

6. Gauhar R, Wilkinson J, Harris J, Manning J, Herrick AL. Calcinosis preferentially affects the thumb compared to other fingers in patients with systemic sclerosis. Scand J Rheumaol. 2016;45:317-20.

7. Gutierrez A Jr, Wetter DA. Calcinosis cutis in autoimmune connective tissue diseases. Dermatol Ther. 2012;25:195-206.

8. Galluccio F, Allanore Y, Czirjak L, Furst DE, Khanna D, MatucciCerinic M. Points to consider for skin ulcers in systemic sclerosis. Rheumatology. 2017;56 (suppl 5):v67-v71.

Copyright by Toshiyuki Yamamoto. This is an open access article distributed under the terms of the Creative Commons Attribution License, which permits unrestricted use, distribution, and reproduction in any medium, provided the original author and source are credited.

Source of Support: Nil, Conflict of Interest: None declared. 